\title{
Role of Different Carbon Source on Phosphate Solubilization by Psychrotolerant Isolate
}

\author{
Kumari Punam Pallavi* \\ Krishi Vigyan Kendra, Harnaut, Nalanda, Bihar-803110, India \\ *Corresponding author
}

\section{A B S T R A C T}

\section{Keywords}

Enterobacter hormachei, NBRIP broth, Phosphate solubilisation, Carbon source, Nitrogen source

Article Info

Accepted:

18 September 2018 Available Online: 10 October 2018
A lab experiment was conducted at the department of microbiology, G. B. Pant University of Agriculture \& technology, Pantnagar. MPS activities were measured in liquid media (NBRIP broth) using Ammonium sulphate as N source, glucose and maltose as a carbon source at $10^{\circ} \mathrm{C}$. Glucose significantly increased MPS activity and this activity was three times (3610.12PPM) in comparison of maltose (1434.99PPM). The mineral phosphate solubilizing activity was strongly associated with the production of gluconic or citric acids. Moreover, isolate (Enterobacter hormachei), maximum ' $\mathrm{P}$ ' solibilization was observed on $7^{\text {th }}$ day of incubation at $10^{\circ} \mathrm{C}$ as compared to $30^{\circ} \mathrm{C}$, when glucose is taken as a carbon source and Ammonium sulphate $\left(\mathrm{NH}_{4}\right)_{2} \mathrm{SO}_{4}$ as nitrogen source.

\section{Introduction}

Phosphorus is one of the major plant nutrients, second only to nitrogen in requirement. However, a greater part of soil phosphorus, approximately $95-99 \%$ is present in the form of insoluble phosphates and hence cannot be utilized by the plants. Biological Nitrogen Fixation depends appreciably on the available forms of phosphorus. ' $\mathrm{P}$ ' is an important structural constituent of nucleic acids, phytin and phospholipids. Plants absorb inorganic form of ' $\mathrm{P}$ ' and make about $0.2 \%$ of their dry weight. They take up inorganic phosphate in two soluble forms: the monobasic $\left(\mathrm{H}_{2} \mathrm{PO}_{4}{ }^{-}\right)$ and the dibasic $\left(\mathrm{HPO}_{4}{ }^{2-}\right)$ ions (Vessey, 2004). However, phosphate anions are extremely reactive and may be immobilized through precipitation with cations such as $\mathrm{Ca}^{2+}, \mathrm{Mg}^{2+}$, $\mathrm{Fe}^{3+}$, and $\mathrm{Al}^{3+}$ depending on the particular properties of soil (Nopparat et al., 2007). To increase the availability of phosphorus for plants, large amounts of fertilizer are being applied to soil. But a large proportion of phosphatic fertilizer applied is quickly transformed to the insoluble forms which decrease the efficiency of fertilizers. The unbalanced use of chemical fertilizer, has led to reduction in soil fertility and to environmental degradation (Gyaneshwar et al., 2002). So, the need of those microbes arose which have the capacity to solubilize phosphorus. These microorganisms are called Phosphate solubilizing micro-organisms (PSMs). Mineral phosphate solubilization is an essential plant growth-promoting ability via 
which PSM have been found to have extensive applications in agriculture as inoculants (Arcand and Schneider 2006; Lucy et al., 2004). Microbial mediated phosphorus management is an eco-friendly and cost effective approach for sustainable development of agricultural crop. Microorganisms are an integral component of the soil phosphorus cycle and are important for the transfer between different pools of soil phosphorus. Phosphate Solubilzing Microorganisms (PSM) through various mechanisms of solubilization and mineralisation are able to convert inorganic and organic soil $\mathrm{P}$ respectively into the bioavailable form facilitating uptake by plant roots. It is important to determine the actual mechanism of $\mathrm{P}$ solubilisation by PSM for optimal utilization of these microorganisms in varied field conditions. Hence it is imperative to better understand the plant-soil-microbial $\mathrm{P}$ cycle with the aim of reducing reliance on chemical $\mathrm{P}$ fertilizers. This has led to increased interest in the harnessing of microorganisms to support $\mathrm{P}$ cycling in agroecosystems. (Sharma et al., 2013)

The mechanism of mineral phosphate solubilization by PSB strains is associated with the release of low molecular weight organic acids which through their hydroxyl and carboxyl groups chelate the cations bound to phosphate, thereby converting it into soluble forms. The phosphate-solubilizing activity is qualitatively assessed by the ability to form solubilization halos (light zones) around the microbial colonies (Mikánova and Nováková, 2002), when they are grown on plates of distinct culture media such as Pikovskaya agar, NBRIP medium (Nautiyal, 2000) and NBRIP-BPB medium (Mehta and Nautiyal, 2001).

Temperature is one of the important factors that immediately affect the interior of the cell. Low temperature habitats are colonized by psychrophiles and psychrotolerant microorganisms, Psychrophiles are those microorganisms whose cardinal growth temperatures are at or below 0,15 , and $20^{\circ} \mathrm{C}$, respectively. Pseudomonas fluorescence, Pseudomonas putida, Pseudomonas striata, Acinetobacter, Enterobacter, Paecilomyces etc. comes under higher psychrophilic 'P' solubilizer. The phosphate solubilizing activity of PSMs is also affected by the presence of various carbon and nitrogen sources. Development of growth and activity of PSMs is very much affected by source of carbon, nature and concentration of salt and pH of soil (Yadav, 2010). Many researchers have studied the effect of various carbon sources on phosphate solubilization (Narsian and Patel, 2000). Further, the glucose as a carbon source show higher levels of phosphorus solubilization as compared to glycerol, maltose, sucrose and galactose. The solubilization of rock phosphate using diverse types of $\mathrm{C}$ sources has been studied by several workers. Rose (1957) showed that glucose or xylose were the best energy sources for fungi in liquid medium, whereas Katznelson and Bose (1959) reported that either yeast extract or soil extract were essential for the proper growth of phosphate solubilizing organisms in liquid or solid medium. They observed that rock phosphate solubilizing bacteria, yeast and fungi utilized a variety of carbon compounds as energy sources, but the amount of phosphate solubilized varied significantly with different sources of energy. Under cultural conditions it has been observed that bacteria are more active in presence of hexoses and pentoses in the medium whereas fungi are equally effective in the presence of hexoses, pentoses as well as disaccharides. Carbon substrates, in soil are available in limited concentration for microbial growth; hence the organisms grow in close vicinity of roots in plant rhizosphere than in non- rhizosphere soil. The plant root exudates provide readily metabolizable carbon and nitrogen compounds 
for the growth of the heterotrophic forms and because of that the bacteria and fungi form an associative symbiosis with the root system to get substrates from the plant roots and provide mineral which normally could not be absorbed by the roots including phosphorus. This experiment was conducted to evaluate the effect of different carbon sources on mineral phosphate solubilising ability of strain Enterobacter hormachei.

\section{Materials and Methods}

\section{Isolation and Identification}

The present experiment was conducted in the laboratory under the Department of microbiology, college of basic science and humanities, G.B. Pant University of Agriculture and Technology, Pantnagar. Strains were isolated from the soil of Almora district located between $29.62^{\circ} \mathrm{N}$ Latitude and $79.67^{\circ} \mathrm{E}$ longitude. The height of experimental site from sea level is $1651 \mathrm{~m}$ and accession no.is HQ222364. Strain was isolate after serial dilution of soil solution on potato and dextrose agar (PDA) plates. Distinct colonies present on the plates were selected, purified by repeated culturing and maintained on PDA slants at $4^{\circ} \mathrm{C}$.

Solubilization index on solid media, growth condition

Strains were checked for phosphate solubilizing ability on Pikovskaya (PVK) agar medium (Pikovskaya, 1948) incorporated with tri-calcium phosphate $\left(\mathrm{Ca}_{3}\left(\mathrm{PO}_{4}\right)_{2}\right)$ by observing the Solubilization index (S.I.). The medium contained $\mathrm{l}^{-1}$ : glucose, $10 \mathrm{~g} ; \mathrm{KCl}$, $0.20 \mathrm{~g} ; \mathrm{Ca}_{3}\left(\mathrm{PO}_{4}\right)_{2}, \quad 5.00 \mathrm{~g} ; \quad\left(\mathrm{NH}_{4}\right)_{2} \mathrm{SO}_{4} \cdot 7 \mathrm{H}_{2} \mathrm{O}$, $0.50 \mathrm{~g} ; \mathrm{MgSO}_{4}, 0.10 \mathrm{~g} ; \mathrm{MnSO}_{4}, 0.0001 \mathrm{~g} ; \mathrm{FeSO}_{4}$, 0.0001g; Yeast extract, 0.50g; Agar, 15g. The $\mathrm{pH}$ of the media was adjusted to 7.0 before autoclaving. Sterilized PVK media was poured into sterilized Petri plates and after solidification of the media, a pinpoint inoculation of this strain was made onto the plates under aseptic conditions. They were incubated at $28 \pm 2^{\circ} \mathrm{C}$ and $10^{\circ} \mathrm{C}$ for 7 days with continuous observation for colony diameter. The formations of halo zone around the growing colony showing phosphate solubilization. Solubilization index was evaluated according to the ratio of the total diameter (colony + halo zone) and the colony diameter.

\section{Growth promotory properties}

\section{Siderophore production}

The chrome azurol sulfonate (CAS) assay[universal assay - Schwyn and Neilands, 1987] was used since it is comprehensive, exceptionally responsive, and most convenient. The Chrome Azurol Sulfonate assay agar was used.

For the qualitative assay, cultures were spot inoculated onto the blue agar and incubated at $37^{\circ} \mathrm{C}$ for $24-48 \mathrm{~h}$. The results were interpreted based on the color change due to transfer of the ferric ion from its intense blue complex to the siderophore. The sizes of yellow orange haloes around the growth indicate total siderophore activity.

\section{IAA production}

For Qualitative estimation of IAA production Tryptone soy broth is used. Tryptone soy broth $(5.0 \mathrm{ml})$ tubes with and without tryptophan $(200 \mu 1 / \mathrm{ml})$ were inoculated with loopful of actively growing bacterial cultures aseptically and incubated for $48 \mathrm{~h}$ at $28^{\circ} \mathrm{C}$ under shaking condition. Cultures were centrifuged at $10,000 \mathrm{rpm}$ for $10 \mathrm{~min}$. $2 \mathrm{ml}$ of Salkowski reagent was added in $1 \mathrm{ml}$ supernatant. The mixture was incubated at $28^{0} \mathrm{C}$ for $25 \mathrm{~min}$. Development of pink colour shows IAA production. 
Solubilization of tri-calcium phosphate in liquid culture

Culture was grown overnight in NBRIP broth media. In addition, to see the effect of different carbon source on ' $\mathrm{P}$ ' solubilization, the NBRIP broth was modified by replacing glucose by maltose as carbon source. The broth $(50 \mathrm{ml})$ was inoculated by this culture and incubated for 10 days at ambient as well as $10^{\circ} \mathrm{C}$. Aliquots were drawn out at $1^{\text {st }}, 3^{\text {rd }} 7^{\text {th }}$ and $10^{\text {th }}$ day of incubation, centrifuged at 4000rpm at room temperature for $10 \mathrm{~min}$ to get clarified supernatant and then $\mathrm{pH}$ of supernatant was measured using $\mathrm{pH}$ meter. The ' $\mathrm{P}$ ' solubilized was measured in culture supernatant using Ion chromatography (Dionex Model).

\section{Results and Discussion}

The bacterium formed yellowish irregular colonies when incubated on nutrient agar at $30^{\circ} \mathrm{C}$ for 1days. Microscopic examination revealed that the isolate was Gram (-ve), and the cells appeared as thick small rods (Fig. 1). Positive reactions were recorded for citrate utilization, Lysine decarboxylase, Ornithrine decarboxylase, Nitrate reduction, glucose, lactose and arabinose utilization (Table 1). Negative reactions were recorded for Urease, Deamination, $\mathrm{H}_{2} \mathrm{~S}$ production, Adonitol and
Sorbitol utilization. The plant growth promotion traits of the isolate were determined on incubation temperature at $30^{\circ} \mathrm{C}$. Siderophore production as measured by the diameter of zone of the colour change of CAS agar. This bacterium shows positive reaction for both Siderophore and Indole acetic acid (IAA) production. Bacterial plant growth promotion is a complex phenomenon which usually observed quantifiable effects includes increase in the plant biomass (Hameeda et al., 2006). Those strains which showed better result for ' $\mathrm{P}$ ' solubilization also has high ability to produce auxin have been reported earlier (Asea et al., 1988). IAA production in the presence of a suitable precursor such as tryptophan has been reported for several other PGPR belonging to Azospirillum, Azotobacter, Bacillus, Burkholderia, Enterobacter, Erwinia, Pantoea, Pseudomonas and Serratia (Gulati et al., 2008; Kumar et al., 2009). This strains could indirectly augmenting the availability of phosphorus, as the siderophore due to their high affinity for iron are also involved in the release of iron bound phosphorus (Pratibha et al., 2010).

The incubation temperature exerted a definite influence on inorganic phosphate (tri-calcium phosphate) solubilization by the bacterium, the $\mathrm{P}$ release being highest at $30^{\circ} \mathrm{C}$ in comparison of $10^{\circ} \mathrm{C}$ (Fig. 2).

Fig.1 Morphological and colony characterization on agar plates (a and b)

a.

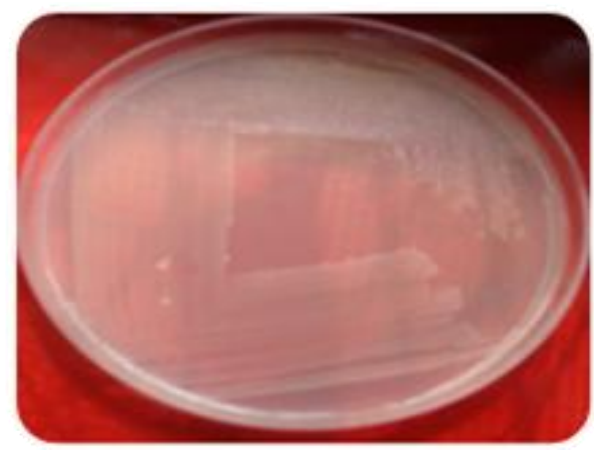

b.

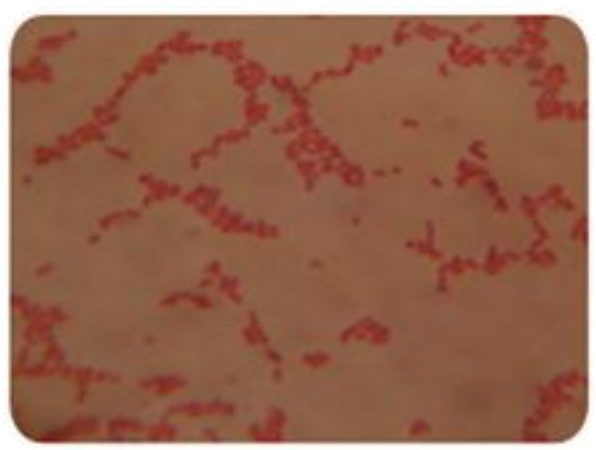


Fig.2 P solubilisation potential of strain on Pikovskaya agar at (a) $10^{\circ} \mathrm{C}$ and (b) $30^{\circ} \mathrm{C}$
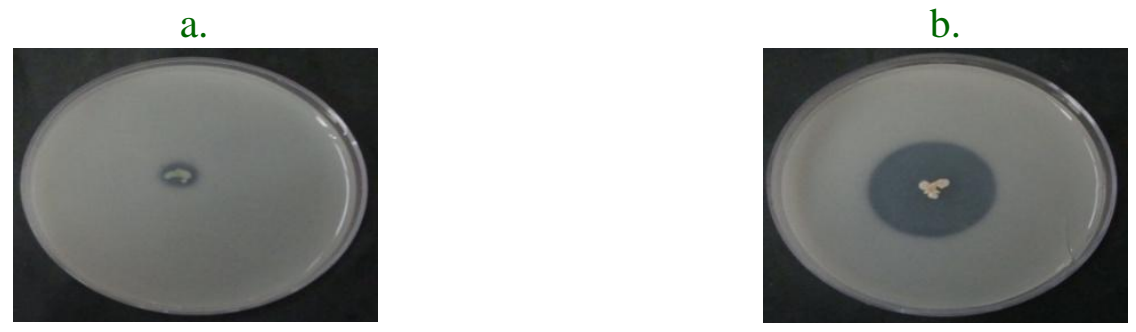

Table.1 Biochemical characteristics of Enterobacter hormachei

\begin{tabular}{|c|l|l|}
\hline No. & \multicolumn{1}{|c|}{ Biochemical tests } & \multicolumn{1}{c|}{ Characteristics } \\
\hline 1. & Shape & Thick small rod \\
\hline 2. & Gram staining & $-\mathrm{ve}$ \\
\hline 3. & Citrate Utilization & $+\mathrm{ve}$ \\
\hline 4. & Lysine decarboxylase & $+\mathrm{ve}$ \\
\hline 5. & Ornithrine decarboxylase & $+\mathrm{ve}$ \\
\hline 6. & Urease & $-\mathrm{ve}$ \\
\hline 7. & Deamination & $-\mathrm{ve}$ \\
\hline 8. & Nitrate reduction & $+\mathrm{ve}$ \\
\hline 9. & $\mathrm{H}_{2} \mathrm{~S}$ & $-\mathrm{ve}$ \\
\hline 10. & Glucose & $+\mathrm{ve}$ \\
\hline 11. & Adonitol & $-\mathrm{ve}$ \\
\hline 12. & Lactose & $+\mathrm{ve}$ \\
\hline 13. & Arabinose & $+\mathrm{ve}$ \\
\hline 14. & Sorbitol & $-\mathrm{ve}$ \\
\hline
\end{tabular}

However, isolate showed some strange response when NBRIP were supplemented with different carbon source. When glucose is taken as a carbon source, isolate showed maximum $\mathrm{P}$ solubilization (3610.12PPM) at $10^{\circ} \mathrm{C}$ on $7^{\text {th }}$ day of incubation with $\mathrm{pH} 4.15$ and $2888.74 \mathrm{PPM}$ at $30^{\circ} \mathrm{C}$ with increase in $\mathrm{pH}$ 5.00. In presence of glucose the organism (Citrobacter freundii) shows maximum solubilization of $\mathrm{P}$, when TCP is used, followed by galactose and then sucrose. Complete order from maximum to lowest is as follows: Glucose> galactose> maltose> sucrose $>$ fructose $>$ lactose $>$ mannose $>$ xylose> mannitol> glycerol. Thus, simple sugars are preferred more as compared to sugar alcohols. Glucose > sucrose > fructose
$>$ galactose $>$ mannitol $>$ mannose $>$ maltose $>$ glycerol > xylose > lactose. (Rathore. P, 2014). Glucose is the most favoured carbon source for max solubilization. Similar results have been reported by Joshi et al., (2012) for Aspergillus. However, when maltose is taken as carbon source isolate solubilized 1776PPM and 1434.99PPM 'P' with $\mathrm{pH} 4.41$ and 4.5 at $30^{\circ} \mathrm{C}$ and $10^{\circ} \mathrm{C}$ incubation temperature. The extent of soluble phosphate was positively correlated with drop in $\mathrm{pH}$ of the culture filtrate. Phosphorus solubilizing microorganisms are reported to dissolve insoluble phosphates by the production of inorganic or organic acids (tartaric, oxalic acid, lactic, citric and gluconic acids) and/or by the decrease of the $\mathrm{pH}$ (Whitelaw, 2000). 
Organic acids may play important role in phosphate solubilization but are not the only possible mechanism for ' $\mathrm{P}$ ' solubilization (Illmer and Schinner, 1992). All the strains showed much higher drop in $\mathrm{pH}$ and simultaneous higher ' $\mathrm{P}$ ' solubilization when glucose was taken as carbon source as compared to Maltose. These results are similar to Pradhan et al., (2005). The effect of different carbon sources (glucose, galactose, fructose) has been determined on the production of enzyme (Qureshi et al., 2010). Mannitol and glucose were also reported to be the best sources for $A$. niger to solubilize phosphorus.

\section{References}

Arcand, M., and Schneider, K.D. 2006. Plant and microbial-based mechanisms to improve the agronomic effectiveness of phosphate rock: a review. An Acad Bras Cienc 78:791-807.

Asea, P.E.A., Kucey, R.M.N. and Stewart, J.W.B. 1988. Inorganic phosphate solubilization by two Penicillium species in solution culture and soil. Soil Biol. Biochem. 20, 459-464.

Gulati, A., Rahi, P., and Vyas, P. 2008. Characterization of phosphate solubilizing fluorescent Pseudomonads from the rhizosphere of sea buckthorn growing in the cold deserts of Himalayas. Curr Microbiol 56:73-79.

Gyaneshwar, P., Naresh Kumar, G., Parekh, L.J., and Poole, P.S. 2002. Role of soil microorganisms in improving $\mathrm{P}$ nutrition of plants. Plant and Soil 245:83-93.

Hameeda, B., Rupela, O. P. \& Reddy, G. 2006. Application of plant growthpromoting bacteria associated with composts and macrofauna for growth promotion of pearl millet (Pennisetum glaucum L.). Biol. Fertil. Soils 43: 221227.
Illmer, P., Schineer F. 1995. Solubilization of inorganic calcium phosphate solubilization mechanisms. Soli Biol Biochem, 27:257-263.

Joshi, Pradnya. A., Shekhawat, Dhiraj B. 2012. Effect of different carbon and nitrogen sources on phosphate solubilization by phosphate solubilizing microorganism. International Journal of Environmental studies. 1(4).

Katznelson, H. and Bose, B. 1959. Metabolic activity and phosphate dissolving ability of bacterial isolates from wheat roots rhizosphere and non-rhizosphere soil. Can. J. Microbiol. 5: 79-85.

Khan AA, Jilani G, Akhtar MS, Naqvi SMS and Rasheed M 2009a: Phosphorus solubilizing bacteria: occurrence, mechanisms and their role in crop production. J Agric Biol Sci 1(1):48-58.

Kumar, K.V., Srivastava, S., Singh, N., and Behl, H.M. 2009. Role of metal resistant plant growth promoting bacteria in ameliorating fly ash to the growth of Brassica juncea. J. Hazard. Mater. 170:51-57.

Lucy, M., Reed, E., Glick, B.R. 2004. Applications of free living plant growth-promoting rhizobacteria. Antonie van Leeuwenhoek 86:1-25.

Mehta, S., and Nautiyal, C.S. 2001. An efficient method for qualitative screening of phosphate-solubilizing bacteria. Curr. Microbiol. 43:51-56.

Mikánova, O., Nováková, J. 2002. Evaluation of the P-solubilizing activity of soil microorganisms and its sensitivity to soluble phosphate. Rostlinná Výroba 48:397-400.

Narsian, V., and Patel, H.H. 2000. Aspergillus aculeatus as a rock phosphate solubilizer. Soil Biol Biochem 32:559565.

Nautiyal, C. S. 2000. An efficient microbiological grown medium for screening phosphate solubilizing 
microorganisms. Fed. Europ. Materials

Soc. Microbiol. Lett. 170:265-270.

Nopparat C., Jatupornpipa M., and Rittiboon A. 2007). Isolation of phosphate solubilizing fungi in soil from Kanchanaburi, Thailand. KMITL KMITL SCI. TECH. J. VOL. 7 NO. S2.

Pikovskaya, RI. 1948: Mobilization of phosphorus in soil in connection with vital activity of some microbial species. Microbiology 1948, 17: 362370.

Pradhan, N., and Sukla. L.B. 2005. Solubilization of inorganic phosphates by fungi isolated from agriculture soil. African Journal of Biotechnology Vol. 5 (10), pp. 850-854.

Pratibha, V., Joshi, R., Sharma, K.C., Rahi, P., and Gulati, A. A. 2010. Cold adapted and rhizosphere competent strain of Rahnella sp. with broad spectrum plant growth promotion potential. J. Microbiol. Biotechnol. 20(12). 1724-1734.

Qureshi, A.S., Dahot, U., and Panhwar, S.I. 2010. Biosynrhesis of Alkaline phosphatase by Escherichia coli. Efr 13 in submerged fermentation. World Appl. Sci. Journal 8:50-56.

Rathore, P. 2014. Role of carbon sources in phosphate solubilization. International journal of scientific research vol. 3, 457-458.

Rose, R. E. 1957. Techniques of determining the effect of micro-organisms on insoluble inorganic phosphates. $N$. Z. J. Sci. Technol. 38: 773-780.

Schwyn, B., and Neilands, J.B. 1987. Universal chemical assay for the detection and determination of siderophore. Anal Biochem 160, 47-56.

Sharma, B. Seema, Sayyed, Z. Riyaz, Trivedi, Mrugesh. H, and Gobi, A. Thivakaran. 2013. Phosphate solubilizing microbes: sustainable approach for managing phosphorus deficiency in agricultural soils. springerplus 2:587

Vessey, J.K. 2004. Plant growth promoting rhizobacteria as biofertilizers. Plant Soil 255: 571-586.

Whitelaw, M.A. 2000. Growth promotion of plants inoculated with phosphate solubilizing fungi. Adv. Agron., 69: 99151.

Yadav, J., Verma, J.P., Yadav, S.K. and Tiwari, K.N. 2010. Effect of salt concentration and $\mathrm{pH}$ on soil inhabiting fungus Penicillium citrinum Thom. For solubilization of tricalcium phosphate. Microbiology Journal 72, 625-630.

\section{How to cite this article:}

Kumari Punam Pallavi. 2018. Role of Different Carbon Source on Phosphate Solubilization by Psychrotolerant Isolate. Int.J.Curr.Microbiol.App.Sci. 7(10): 2597-2603. doi: https://doi.org/10.20546/ijcmas.2018.710.301 